\title{
Movimento dos Trabalhadores Rurais Sem Terra e a formação para a igualdade de gênero
}

\author{
Jeniffer Ribeiro Pessôa ${ }^{1}$, Neusa Maria Dal Ri ${ }^{2 \mathrm{i}}$ \\ ${ }^{1}$ Universidade Estadual Paulista Julio de Mesquita Filho - UNESP. Faculdade de Filosofia e Ciências. Programa \\ de Pós-Graduação em Educação. Avenida Higino Muzzi Filho, 737. Setor Universitário. Marília-SP. \\ Brasil. jenifferpessoa.adv@ hotmail.com.br. ${ }^{2}$ Universidade Estadual Paulista Julio de Mesquita Filho - UNESP.
}

RESUMO. O Movimento dos Trabalhadores Rurais Sem Terra (MST) foi constituído em 1984 com o principal objetivo de lutar pela reforma agrária no Brasil. Com mais de 30 anos de história, o MST, além de organizar a produção e a intervenção política, construiu uma obra educacional importante para os Sem Terra, e uma formação voltada para a mudança de valores. Dentre esses valores destacamos a luta pela igualdade de gênero. Desse modo, o principal objetivo deste artigo é apresentar aos leitores uma análise das políticas de gênero do MST, destacando a ligação desse tipo de política com a formação dos Sem Terra. Os procedimentos adotados foram a pesquisa documental e a pesquisa bibliográfica. Para a coleta de dados foram utilizadas as publicações oficiais do MST, textos elaborados por seus militantes e a literatura especializada sobre a temática. A análise nos levou a concluir que o Movimento, desde sua criação, tem produzido textos teóricos e desenvolvido ações práticas tentando ampliar a participação das mulheres na produção, nos coletivos decisórios e coordenações políticas; garantir e ampliar os direitos jurídicos das mulheres; combater a violência contra a mulher; e introduzir a igualdade de gênero nos seus cursos de educação formal e nos de formação. Para tanto, o MST elaborou propostas estratégicas e criou um Setor de Gênero voltado à promoção da igualdade de gênero e à participação igualitária.

Palavras-chave: MST, Igualdade de Gênero, Educação. 


\title{
Movement of Landless Rural Workers and Training for Gender Equality
}

\begin{abstract}
The Landless Rural Workers Movement (MST) was formed in 1984 with the main objective of fighting for agrarian reform in Brazil. With more than 30 years of history, the MST, in addition to organizing production and political intervention, has built an important educational work for the Landless and a formation focused on the change of values. Among these values we highlight the struggle for gender equality. Thus, the main objective of this article is to present to the readers an analysis of the MST's gender policies, highlighting the connection of this type of policy with the formation of the Landless. The procedures adopted were documentary research and bibliographic research. For the collection of data, the official MST publications, texts prepared by its members and specialized literature on the subject were used. The analysis led us to conclude that the Movement, since its inception, has produced theoretical texts and developed practical actions trying to increase the participation of women in production, decision-making bodies and political coordination; Guarantee and expand the legal rights of women; Combat violence against women; And introduce gender equality in their formal education and training courses. To this end, the MST elaborated strategic proposals and created a Gender Sector focused on the promotion of gender equality and equal participation.
\end{abstract}

Keywords: MST, Gender Equality, Education. 


\title{
Movimiento de los Trabajadores Rurales Sin Tierra y la formación para la igualdad de género
}

\begin{abstract}
RESUMEN. El Movimiento de los Trabajadores Rurales Sin Tierra (MST) fue constituido en 1984 con el principal objetivo de luchar por la reforma agraria en Brasil. Con más de 30 años de historia, el MST, además de organizar la producción y la intervención política, construyó una obra educativa importante para los Sin Tierra, y una formación orientada al cambio de valores. Entre estos valores destacamos la lucha por la igualdad de género. De este modo, el principal objetivo de este artículo es presentar a los lectores un análisis de las políticas de género del MST, destacando la conexión de ese tipo de política con la formación de los Sin Tierra. Los procedimientos adoptados fueron la investigación documental y la investigación bibliográfica. Para la recolección de datos se utilizaron las publicaciones oficiales del MST, textos elaborados por sus militantes y la literatura especializada sobre la temática. El análisis nos llevó a concluir que el Movimiento, desde su creación, ha producido textos teóricos y desarrollado acciones prácticas intentando ampliar la participación de las mujeres en la producción, en los colectivos decisorios y coordinaciones políticas; garantizar y ampliar los derechos jurídicos de las mujeres; combatir la violencia contra la mujer; e introducir la igualdad de género en sus cursos de educación formal y de formación. Para ello, el MST elaboró propuestas estratégicas y creó un Sector de Género orientado a la promoción de la igualdad de género ya la participación igualitaria.
\end{abstract}

Palabras clave: MST, Igualdad de Género, Educación. 


\section{Introdução}

No período de 1964 a 1985 o Brasil esteve sob o governo militar. O cenário político-econômico dessa época e a luta contra a ditadura militar levada a cabo por vários setores das classes média e trabalhadora criaram condições para o surgimento de novos movimentos sociais no país. Dentre esses movimentos, destacase o Movimento dos Trabalhadores Rurais Sem Terra (MST), fundado oficialmente em 1984.

Segundo Bauer (2009, p. 25), o MST “... nasceu em um processo de enfrentamento e resistência contra a política de desenvolvimento agropecuário instaurada durante o regime militar, no período compreendido entre 1978 e 1985 ... luta contra a expropriação e a exploração do desenvolvimento do capitalismo".

Assim que fundado, o Movimento estipulou três objetivos principais.

Em 1984, os trabalhadores rurais que protagonizavam essas lutas pela democracia da terra e da sociedade se convergem no $1^{\circ}$ Encontro Nacional, em Cascavel, no Paraná. Ali, decidem fundar um movimento camponês nacional, o MST, com três objetivos principais: lutar pela terra, lutar pela reforma agrária e lutar por mudanças sociais no país (MST, 2016a, p. 1).
A luta por mudanças sociais é entendida pelo MST como uma transformação dos Sem Terra em sujeitos sociais, ou seja, trata-se de um processo educativo, de formação humana.

Ao longo de sua história, de mais de 30 anos, o MST foi construindo um projeto educacional denominado Pedagogia do Movimento. Na construção de sua proposta educacional, o Movimento elencou seus princípios filosóficos e pedagógicos, que “... são os resultados de práticas realizadas, das experiências que estamos acumulando nestes anos de trabalho" (MST, 1996a, p. 4). Esses princípios são consoantes com a visão de mundo e com objetivos políticos e educacionais do MST e um dos pontos relevantes do seu projeto educativo é a bandeira pelas mudanças sociais, dentre as quais destacamos a igualdade de gênero.

Os princípios filosóficos e pedagógicos da educação do MST incorporam suas concepções de educação, a realidade e as contradições que homens e mulheres Sem Terra vivem no campo, e apontam caminhos para a construção de um novo conhecimento, que nasce das contradições da sociedade capitalista, e que é expresso no movimento das classes em luta impulsionando mudanças nas relações sociais, no modo de produção e criando possibilidades de superação das desigualdades de classe, gênero, raça com 
o objetivo de contribuir para a construção de um sistema econômico socialmente justo e com uma cultura solidária. Todos os “... princípios pedagógicos que tratamos até aqui, tem como centro a pessoa, só que não isolada, individual, mas sim como sujeito de relações com outras pessoas, com coletivos, e com um determinado contexto histórico". (MST, 2005, p. 176).

... tratar das questões da educação de gênero na perspectiva dos movimentos sociais. Há que se tomar em conta que existem dois elementos basilares da fundamentação das relações sociais, quais sejam: a divisão social e sexual do trabalho e a cultura que se reproduz e justifica o sistema socioeconômico e político. Portanto, há que se buscar entender como estão se dando essas divisões nas relações cultivadas nas práticas educativas destes movimentos sociais e da sociedade como um todo (Araujo, 2014, p. 2).

Desse modo, o principal objetivo deste texto é apresentar uma análise das políticas de gênero do MST e, em especial, a ligação dessa política com a formação educacional desenvolvida pelo Movimento. Os procedimentos de pesquisa utilizados foram a pesquisa documental e a pesquisa bibliográfica. Para a coleta de dados, e posterior análise, foram utilizadas as publicações oficiais do MST, textos elaborados por seus militantes e a literatura especializada sobre a temática.
Em grande parte dos documentos dos diferentes setores do MST, tais como o Boletim da Educação (1992a, , 1996a, -), Caderno da Educação (1992b, 1994), Caderno de Formação (1986b, 1988, 1989, 1999a), Caderno de Estudo (1996b, 1998, 2001b, 2003, 2004-) são citadas formas de ampliar a participação das mulheres e crianças no Movimento, e a importância da igualdade de gênero em todos os âmbitos, setores e instâncias do Movimento.

As publicações da década de 1990 a 2000 se constituíram principalmente pela busca de estratégias para colocar em prática os valores e normas considerados importantes e aprovados nos Congressos.

No ano de 2000 ocorreu a criação do Setor de Gênero. Os documentos desta década permitiram ampliar a discussão e as ações para que as mulheres tivessem voz e poder de decisão no Movimento e fossem tratadas com respeito e igualdade, além de ter proporcionado a publicação de textos específicos e incluído o tema na pauta dos Encontros estaduais e nacionais ${ }^{\mathrm{ii}}$. Desse modo, as atuações e preocupações com a formação educacional dos/das integrantes do Movimento proporcionam, de maneira contínua, a elaboração e publicação de documentos que trazem contribuições teóricas e empíricas para a atualidade e, em especial, para o estudo da igualdade de gênero. 


\section{MST e a questão de gênero}

O MST reconhece a dificuldade de abordar o tema gênero, pois se trata de concepções e valores presentes nas relações sociais cotidianas e que são considerados naturais na e pela sociedade. Além disso, “... há a dificuldade de relacionar o conceito com a realidade, pois trata-se de uma abordagem nova para o velho problema da desigualdade entre homens e mulheres" (MST, 2003, p. 7).

As relações sociais de gênero, classe e etnias, tem por fundamento a estrutura que se desenvolve a partir da forma como a sociedade organiza e controla a produção e a reprodução da existência. É a partir das bases materiais que a sociedade, em cada época organiza as suas instituições para dar conta de reproduzir e manter o equilíbrio de determinadas configurações econômicas, políticas e ordens sociais e de poder. Entre estas instituições se inserem a educação, vista aqui em uma perspectiva mais ampla do que os complexos sistemas escolares (Araújo, 2014, p. 1).

Segundo o MST (2003, p. 27, grifos do autor), a origem do tratamento da questão de gênero ocorreu da seguinte forma.

Em 1955 surge pela primeira vez o uso da palavra gênero para indicar os papéis de gênero, atribuídos diferentemente a homens e mulheres e foi usado pelo pesquisador John Money. Em 1968, Robert Stoler estabeleceu mais nitidamente a diferença entre os conceitos de sexo e gênero. Nos anos 80, um grupo de mulheres inglesas começam a usar o termo gênero num estudo sobre relacionamentos entre homens $\mathrm{e}$ mulheres na família e na sociedade. Destaca-se a pesquisadora Joan Scott com seu trabalho: 'Gênero: uma categoria útil para a análise histórica'. (Brasil, publicado em 1991, SOS Corpo, Recife, PE).

O Movimento reconhece que apenas recentemente este tema passou a ser estudado por seus membros, pois ainda surgem muitas dúvidas acerca do conceito de gênero. Para melhor compreensão do que significa gênero, o MST (2003, p. 7) traz o conceito do Dicionário Aurélio.

Gênero [Do lat. Genus, eris, 'classe', 'espécie', poss. pelo pl. lat. Genera, ou pelo lat. * generum, com mud. de declinação.] Antrop.

A forma culturalmente elaborada que a diferença sexual toma em cada sociedade, e que se manifesta nos papéis e status atribuídos a cada sexo e constitutivos da identidade sexual dos indivíduos.

A definição do dicionário sobre o conceito de gênero destaca que as diferenças entre homens e mulheres são culturalmente construídas em cada sociedade. Essas construções são manifestas principalmente nos papéis sociais que cada um desempenha e o valor dado ao trabalho desempenhado por cada indivíduo de acordo com o gênero. Cada sociedade constrói culturalmente o papel social do masculino e feminino, ditando as 
profissões, estilos e atributos em geral adequados a cada um. Portanto, gênero é usado para indicar a construção social do ser homem e do ser mulher como categoria social.

Partindo do entendimento de que gênero é uma construção social, o conceito busca derrubar "... uma velha compreensão de que homens e mulheres têm funções sociais porque são biologicamente diferentes" (MST, 2003, p. 7-8).

Para aperfeiçoar o conceito de gênero, o MST utiliza diferentes contribuições teóricas formuladas por diferentes autoras, destacando as relacionadas com o movimento feminista. Dentre os conceitos apresentados, destacamos o conceito que o MST traz de Nalu Faria e Miriam Nobre (MST, 2003, p. 9), que afirmam que o conceito de gênero trouxe avanço nas relações, pois permite uma análise mais ampla.

Por isto, gênero, um termo emprestado da gramática, foi a palavra escolhida para diferenciar a construção social do masculino e feminino do sexo biológico. Gênero é um conceito relacional, ou seja, que vê um em relação ao outro e considera que estas relações são de poder e hierarquia dos homens sobre as mulheres.

Outra concepção que o MST trabalhou e merece destaque é aquela assumida pelo movimento feminista marxista, que trata das desigualdades entre homens e mulheres nas relações sociais. Para tanto o Movimento traz o pensamento de Clara Araujo (MST, 2003, p. 10-11).

$O$ conceito de gênero surge da tentativa de compreender como a subordinação é reproduzida e a dominação masculina é sustentada em suas múltiplas manifestações, buscando incorporar as dimensões subjetiva e simbólica de poder, para além das fronteiras materiais e das conformações biológicas. A possibilidade de pensar as práticas materiais e, ao mesmo tempo, as construções simbólicas, evitando o essencialismo biológico ou a sustentação exclusiva na dimensão econômica, fez com que esse conceito fosse assumido também pelo feminismo de base marxista, preocupado em responder à permanência de relações de opressão entre homens e mulheres, mesmo em contextos econômicos e políticos diferenciados. Trata-se de importante recurso analítico para pensar a construção/desconstrução das identidades de gênero, isto é, os caminhos através dos quais os atributos e lugares do feminismo e do masculino são social e culturalmente construídos, muito mais como significados do que como essência. Gênero é relacional e, nesse sentido, um gênero só existe em relação com o outro. Essa característica permite considerar que tanto o processo de dominação quanto o de emancipação envolvem relações de interação, conflito e poder entre homens e mulheres. Numa perspectiva política, nos obriga a ampliar o olhar sobre os atores. $\mathrm{O}$ problema deixa de ser apenas das mulheres, requerendo alterações nos lugares, práticas e valores dos atores em geral. Esse conceito contribuiu para incorporar na agenda feminista a luta no plano da cultura e a ideologia, fornecendo 
um espaço para a subjetividade na construção e reprodução dos lugares e significados socialmente identificados com o masculino e o feminino.

Outra distinção importante a ser destacada diz respeito aos termos sexo, gênero e identidade sexual. Por vezes sexo e gênero são tratados como sinônimos, contudo, existem diferenças. Para o MST (2003, p. 11) os conceitos e níveis têm as seguintes definições: "1. O sexo: macho e fêmea; 2. O gênero: feminino e masculino; 3. a identidade psicossexual: heterossexual, bissexual, homossexual". Sexo indica as características biológicas que tornam o ser macho ou fêmea, enquanto gênero indica papéis culturalmente impostos que devem ser atribuídos ao homem ou a mulher. Em geral, ocorrem discriminações em relação às atitudes que não se encaixam nos modelos ou no padrão considerado normal pela sociedade. Nesse sentido, o MST (2003, p. 28) cita a ilustre frase de Simone de Beauvonoir: “... cada ser humano nasce macho ou fêmea (sexo), mas torna-se homem ou mulher (gênero): Não se nasce mulher, torna-se mulher". Assim, a luta pela igualdade de gênero não busca acabar com as diferenças naturais entre os sexos, mas sim garantir a compreensão e o respeito às características de cada indivíduo.
Na sociedade em geral e na esfera da produção, os homens são considerados como fortes e empreendedores, enquanto as mulheres são vistas como delicadas e mães, por exemplo. Disso deriva a visão de que algumas profissões são para homens e outras poucas para mulheres. Essas características são também utilizadas para justificar distinções e desigualdades sociais, justificadas nas diferenças biológicas, revelando a desigualdade de gêneros. Contudo, essas características são socialmente construídas, não são naturais. Desse modo, para a conquista da igualdade há necessidade de reconstrução desses conceitos forjando-se novos valores e nova construção social.

Além de compreender as diferenças entre masculino e feminino, o conceito de gênero trouxe muitas outras contribuições. O MST destaca as contribuições dadas por Nalu Faria e Miriam Nobre (MST, 2003, p. 13-14).

1. Ao afirmar a construção social dos gêneros, coloca que as identidades e papéis masculino e feminino não são um fato biológico, vindo da natureza, mas algo construído historicamente e que, portanto, pode ser modificado. A construção social dos gêneros tem uma base material (e não apenas ideológica) que se expressa na divisão sexual do trabalho.

2. As relações de gênero são hierárquicas e de poder dos homens sobre as mulheres. Essas relações de poder são as primeiras vividas por 
todas as pessoas e é com elas que começamos a apreender o mundo. $\mathrm{Ou}$ seja, a relação das pessoas com o mundo se inicia a partir dessas relações de poder e se reproduz no conjunto da sociedade e das instituições. Sendo assim, modificar essas relações implica uma nova correlação de forças, construída pela auto-organização das mulheres e mais favorável a elas.

3. As relações de gênero estruturam o conjunto das relações sociais e, portanto, não existe uma oposição entre questão das mulheres (que seria específica) e questão da sociedade (que seria geral). Os mundos do trabalho, da política e da cultura também se organizam conforme inserção de mulheres e homens, a partir de seus papéis masculinos e femininos. Portanto, não existe uma luta geral e depois uma específica, mas em todas as situações que queremos modificar, temos que considerar a superação das desigualdades entre mulheres $\mathrm{e}$ homens.

4. Gênero supera as antigas dicotomias entre produção $\mathrm{e}$ reprodução, público e privado e mostra como mulheres e homens estão ao mesmo tempo em todas essas esferas, só que a partir de seu papel masculino e feminino. Por exemplo, os homens também vivem no espaço doméstico e mesmo aí a eles são destinados tarefas que poderiam ser interpretadas como produtivas, tais como trocar lâmpadas ou consertar um móvel quebrado.

5. A análise das relações de gênero só é possível considerando a condição global das pessoas - classe, raça, idade, vida urbana ou rural, e monto histórico em que se dá. Dessa forma, embora existam muitos elementos comuns na vivência e condição das mulheres, nem todas foram criadas para exercerem $\mathrm{o}$ mesmo papel, sem nenhuma diferenciação. Por exemplo, em nosso país uma branca rica é ensinada para exercer seu papel feminino de uma maneira bem diferente de uma negra pobre, com relação a que tipo de esposa cada uma deve ser, as tarefas de mãe, o cuidado com o corpo e a aparência, as boas maneiras, etc.

Para as autoras, as relações de desigualdade de gênero, que são culturalmente construídas, estão presentes no contexto da luta de classes. A desigualdade social é parte da estrutura capitalista e está presente nas relações de produção, educação e gênero. Assim, a reprodução dessas desigualdades, que aparecem como sendo naturais, bem como dos valores e comportamentos, é realizada de acordo com os interesses da classe hegemônica. Os homens são os chefes de família, trabalhadores e provedores do lar, portanto, portadores dos recursos financeiros e com o direito de tomar as decisões da família, enquanto as mulheres devem se limitar aos cuidados dos filhos e da casa, trabalho não reconhecido e não remunerado, além do fato de sofrerem opressões, dominação e violência. $\mathrm{Na}$ atualidade, apesar de as mulheres estarem trabalhando e exercendo várias profissões, o trabalho doméstico continua sendo de sua responsabilidade, beneficiando os homens e, sobretudo, as relações sociais capitalistas. 
A categoria gênero trouxe avanços para o MST, pois permitiu novas reflexões e a construção de novos valores em relação à igualdade. Nesse sentido, a luta deve ser de todos, homens e mulheres rompendo os modelos até então reproduzidos.

\section{Política de gênero do MST}

A preocupação com a igualdade de gênero e com a educação esteve presente no MST desde a sua criação, isso porque um dos seus objetivos estratégicos é a luta pela mudança social, da qual faz parte a construção de novos valores. Assim, a questão de gênero é importante, pois o Movimento aponta que as desigualdades estão presentes na sociedade e seus integrantes não estão imunes à reprodução dos valores dominantes. Isso significa que os Sem Terra também reproduzem a desigualdade de gênero em seu cotidiano. Para mudar a realidade é preciso, primeiro, reconhecer as desigualdades presentes e, segundo, lutar para transformar os valores até então disseminados.

A distribuição e o exercício de poder dentro das organizações populares é bastante desfavorável às mulheres. Partindo da compreensão que as relações de gênero são relações de poder, é importante refletir no cotidiano do MST como essa relação de poder/relação de gênero se manifesta (MST, 2003, p. 22).
No sentido de debater e promover a igualdade de gênero, o MST trabalha com discursos, ações e práticas para a formação dos militantes forjando novos valores, conscientizando sobre a necessidade de mudanças e tentando romper com a ideologia dominante.

A primeira ação do Movimento no sentido de promover a igualdade de gênero ocorreu em seu I Congresso Nacional realizado em 1985, no qual foram aprovadas normas gerais e a organização de comissões de mulheres para discutir problemas específicos; estimular a participação das mulheres em todos os níveis de atuação, instâncias de poder e representatividade; combater toda forma de discriminação das mulheres; e lutar contra o machismo.

$\mathrm{O}$ primeiro Caderno de Formação intitulado Organização do Movimento de 1986, trouxe orientações práticas do Movimento. No item sobre a organização interna, lê-se que “... em todos os níveis de organização: núcleos de base, nos grupos de ocupação, comissão municipal, comissão dos movimentos regionais, comissão estadual, e coordenação nacional, deve ter companheiras mulheres trabalhadoras" (MST, 1986a, p. 9).

No mesmo ano foi lançado o Caderno de Formação n. 10 com o título $A$ luta continua: como se organizam os 
assentados. $\mathrm{O}$ texto apresenta as resoluções políticas do Movimento e, dentre outras decisões, destacamos aquelas que dizem respeito às mulheres agricultoras. Neste texto constam oito resoluções que apontam decisões a fim de garantir a igualdade entre homens e mulheres, além do empoderamento feminino, buscando que as mulheres militantes sejam mais que donas de casa, que elas possam trabalhar efetivamente no trabalho rural, e nos setores do Movimento (MST, 1986b, p. 33).

1. ${ }^{\circ}$ ) Que os homens apoiem as iniciativas e a organização das mulheres, dando força para suas esposas participarem.

$\left.2 .^{\circ}\right)$ Que os assentamentos onde as mulheres já têm organização ajudem as mulheres dos outros assentamentos onde não há esta organização e está difícil de começar a nível de estado.

3. ${ }^{\circ}$ Que as mulheres assentadas incentivem e animem as mulheres dos sem terra a participar das reuniões e do Movimento.

4. $\left.{ }^{\circ}\right)$ Que nas comissões dos assentamentos, estaduais e nacional, as mulheres conquistem $\mathrm{o}$ seu espaço, sem paternalismos, mas sendo-lhes reconhecida a capacidade de ocupar tais cargos.

5. $\left.{ }^{\circ}\right)$ Que as secretarias estaduais dos sem terra enviem material para ajudar a organização das mulheres nos assentamentos.

$\left.6^{\circ}{ }^{\circ}\right)$ Que as mulheres participem na renovação sindical, exijam o direito de associação e conquistem seu espaço nas diretorias.

7. $\left.{ }^{\circ}\right)$ Que as mulheres votem nos candidatos que são mulheres e/ou trabalhadores que defendem os direitos dos assentados e das mulheres na Constituinte.

8. $\left.{ }^{\circ}\right)$ Que, ao tirar documentos em que conste a profissão, as mulheres possam colocar que são trabalhadoras rurais, não aceitando a simples denominação 'doméstica' ou 'do lar'. Isto é importante agora na troca de título de eleitor e em caso de título de eleitor e em caso de núpcias na certidão de casamento, entre outros (MST, 1986b, p. 33).

Outro texto publicado no ano de 1986 é o livro intitulado Construindo o Caminho. Em seu estudo intitulado Subjetividade e gênero no MST, Melo (2007, p. 115) indica que nesta obra constam, dentre outros assuntos as “... primeiras resoluções aprovadas pelo MST como diretrizes para tentar solucionar o problema, surgido em seus assentamentos, relativo à participação política das mulheres na luta pela reforma agrária".

O livro trata ainda do posicionamento sobre a questão da mulher assentada e "... a existência desta resolução denota que o processo de construção de novas formas de relações humanas nas comunidades assentadas pelo movimento começava a ser colocado na pauta dos problemas a serem enfrentados e solucionados no MST" (Melo, 2007, p. 120).

O Caderno de Formação n. 12, fruto do $3^{\circ}$ Encontro Nacional que aconteceu em janeiro de 1987, trata das prioridades do MST. Uma das prioridades apontadas é 
"ampliar o movimento em todos os sentidos" e uma das formas para isso é "... estimular maior participação das mulheres" (MST, 1987, p. 8). No que trata da organização interna dos assentados, mais uma vez verificamos a preocupação com “a organização das mulheres" (MST, 1987, p. 15). Ainda, nos destaques das datas importantes para o Movimento, aparece no calendário, com grande importância, o "dia 8 de março: dia internacional da mulher trabalhadora" (MST, 1987, p. 18).

Todavia, o MST tinha clareza acerca das dificuldades a serem ultrapassadas para a conquista da igualdade,

No entanto, é preciso ficar bem claro que a mulher não espere sua emancipação automática no socialismo. Ao longo de toda história a mulher da classe dominada foi vítima de uma dupla exploração uma opressão de classe e uma opressão de gênero - oprimida por ser proletária; oprimida por ser mulher. Durante todo esse tempo, viveu afundada no mais profundo obscurantismo, vítima de preconceitos, preconceitos esses compartilhados, inclusive, por seus companheiros. Desse modo, cabe à mulher, lutar em duas frentes: por sua classe, lutar porque é oprimida como classe e lutar porque é oprimida enquanto sexo (MST, 1988, p. 16).

\section{A mulher nas diferentes sociedades é} um Caderno de Estudo produzido em 1988 e assinado pela equipe de mulheres do MST. Na sua apresentação consta um indicativo de que a participação das mulheres nos movimentos populares tem sido importante para garantir conquistas, porém, um dos problemas apontados é que as mulheres não tinham as mesmas oportunidades que os homens para se capacitarem. Assim, o objetivo do caderno foi o de ser "... um primeiro passo no sentido de despertar sua atenção para questões que interessam à mulher e a toda a classe trabalhadora" (MST, 1988, p. 3).

O material está dividido em cinco capítulos: 1. A mulher na sociedade primitiva; 2. A mulher na sociedade escravista; 3. A mulher na sociedade feudalista; 4. A mulher na sociedade capitalista; 5. A mulher na sociedade numa nova sociedade.

No ano seguinte, em 1989, foi publicado o Caderno de Formação Normas Gerais do MST, apresentando

... resoluções que denotam a permanência e os efeitos dos embates internos relativos à transformação das relações entre homens e mulheres, como aspecto 'novo' proposto pelo projeto social do MST. Prova disto é a publicação da resolução referente à Articulação das mulheres no MST apresentada no oitavo capítulo do livro ... (Melo, 2007, p. 123, grifos da autora).

As orientações apresentadas tratam do incentivo à participação das mulheres em todos os níveis de atuação, do combate a qualquer tipo de discriminação das mulheres e do estímulo à organização das 
mulheres em comissões em nível nacional. Segundo Melo (2007), as resoluções tiveram por objetivo buscar soluções para o problema das discriminações de gênero e fazer com que a luta pela igualdade deixe de ser reservada ao coletivo de mulheres, e passe a ser um princípio político norteador dos processos de lutas do MST. Desse modo, as resoluções trouxeram uma atenção mais apurada à participação política das mulheres e à igualdade de gênero.

Em 1995, ocorreu o I Encontro de Mulheres Trabalhadoras Rurais, que reuniu mulheres de várias organizações rurais e no qual se discutiu a necessidade de incorporação dos direitos às trabalhadoras rurais já conquistados pelas trabalhadoras urbanas, tais como, salário-maternidade, auxílio acidente de trabalho, etc.

No Jornal Sem Terra, publicado em novembro de 1995, ficam claras as influências deste Encontro no MST. O jornal trata da relação entre gênero e classe e afirma que “... esta combinação de luta é fundamental não só para a construção de novas relações de gênero, mas de um projeto de sociedade democrática e popular" (JST, 1995, p. 12). Em março de 1996, o Jornal mais uma vez demonstra a preocupação da luta de classe e das mulheres afirmando que “... O MST deve lutar também contra o machismo" (JST, 1996, p. 4).

Até o ano de 1996 as cartilhas eram elaboradas pelo Coletivo Nacional de Mulheres. Posteriormente, a partir de 1998 as cartilhas passaram a ser assinadas pelo Coletivo Nacional de Gênero. O nome do Coletivo foi mudado novamente, quando passou a ser chamado de Setor Nacional de Gênero na primeira cartilha em 1999. Os conteúdos das cartilhas apresentam uma discussão acerca da definição de gênero e apontam para a construção de novas relações de gênero no MST. Com esse intuito, e para o fortalecimento teóricoprático dessa política no Movimento, o Coletivo foi organizado como Setor oficialmente no ano de 2000.

Uma das coordenadoras do Setor Nacional de Gênero nos revelou que havia muita dificuldade de avançar na participação das mulheres e que era necessário que esta temática fizesse parte da própria estrutura organizativa do Movimento dividida em Setores e predominantemente ocupados por homens (Gonçalves, 2010, p. 5).

A primeira cartilha organizada pelo Coletivo Nacional de Mulheres em 1996 surgiu sob o título A questão da mulher no MST (1996b), e apresenta um plano de trabalho oriundo do I Encontro Nacional das Mulheres Militantes do MST, realizado de 25 a 28 de maio daquele ano. "Nesse 
encontro, além de discutirem sobre a construção histórica da dominação de gênero nas relações sociais, discutiram sobre o cotidiano a mulher no processo de luta pela terra e sua inserção nas instâncias decisórias do movimento" (Melo, 2007, p.132).

Segundo a cartilha (MST, 1996b, p. 7), as mulheres enfrentam discriminação nos acampamentos e assentamentos e sentem a necessidade de uma estrutura que possibilite a sua participação. Os desafios para o Coletivo Nacional de Mulheres eram muitos, para tanto, foram traçados objetivos estratégicos como construir novos valores no cotidiano, tratar a questão de gênero enquanto princípio, massificar e organizar a participação das mulheres. Além de objetivos específicos como criar mecanismos para garantir a participação das mulheres em todos os níveis e, criar novas relações para participação igualitária das mulheres nas relações política, econômica e social.

Primeiramente, a cartilha apresenta um breve histórico de três documentos diferentes que tratam da questão da mulher. $\mathrm{O}$ primeiro documento analisado na cartilha foi escrito em 1989 na primeira edição das Normas gerais do MST, na qual foi incluído um capítulo sobre a 'articulação das mulheres', destacando atitudes como estimular a participação das mulheres, combater todos os tipos de discriminação e lutar contra o machismo; além de chamar a atenção para a necessidade de estimular a organização de comissões de mulheres em nível nacional, responsáveis pelas políticas propostas para o movimento (MST, 1996b, p. 5).

O segundo texto apresentado é o Documento Básico do MST, de 1993. No artigo 45 é enfatizada a necessidade de “... considerar as questões específicas das mulheres e sua participação como parte integrante das reivindicações e da organização, tratando como classe e não enquanto gênero" (MST, 1996b, p. 5-). Além disso, no artigo 152 ressalta-se que é preciso “... garantir a participação das mulheres em todos os níveis da cooperação agrícola e, sobretudo estimular sua participação no trabalho produtivo, como também combater as desigualdades e o tradicionalismo que existe no meio camponês" (MST, 1996b, p. 5-6).

O terceiro documento apresentado é o Programa Agrário, de 1995. Nos objetivos gerais, ponto 6 do documento, demonstra-se a necessidade de "combater todas as formas de discriminação social e buscar a participação igualitária da mulher" ((MST, 1996b, p. 6)Autor, Ano, p.?); enquanto o ponto 7 trata da situação da mulher no campo, declarando que as mulheres não recebem pelo seu trabalho, 
nem participam das decisões econômicas. Ressalta, ainda, que entre as pessoas que vivem no campo, certamente as mulheres e crianças são as que mais sofrem e que a isso é acrescida a "condição generalizada de preconceitos e discriminações pela prática do machismo no meio rural, que submete a mulher a uma condição inferior" (MST, 1996b, p. 6).

Para pôr em prática a construção das novas relações de gênero o programa traça alguns objetivos:

\section{Nossos objetivos estratégicos:}

a) construir novos valores no cotidiano (família, militância, direções , postura pessoal);

b) tratar a questão de classe e gênero enquanto princípio;

c) massificar e qualificar a participação das mulheres;

d) dar organicidade à participação das mulheres;

\section{Nossos objetivos específicos:}

a) criar mecanismos para garantir a participação das mulheres em todos os níveis (creches e outras);

b) criar novas relações em que os resultados políticos, econômicos e sociais sejam distribuídos de forma igualitária entre homens e mulheres; (MST, 1996b, p. 7).

Para tanto, o Movimento estabelece níveis de ação, em que uma das tarefas do coletivo consistia em fazer com que nas instâncias do MST “... todos os setores discutam e encaminhem concretamente a questão de gênero" e “... garantir espaços de estudo e discussão em instâncias criando mecanismos de participação"
(MST, 1996b, p. 8). Além disso, a cartilha traz outras orientações gerais, encaminhamentos práticos, como estruturar o coletivo, escrever publicações em cadernos de formação, cartilhas e realização de campanhas.

A questão da mulher recebeu maior destaque na cartilha seguinte, de 1998, com o título de Compreender e construir novas relações de gênero. A apresentação da coletânea de textos é atribuída ao novo Coletivo Nacional de Gênero, e a publicação deveria servir “... de documento permanente de estudo e aprofundamento entre a militância do MST, para compreendermos e construirmos novas relações de gênero no nosso dia-a-dia" (MST, 1998, p. 5). O expediente da coletânea ainda é assinado pelo Coletivo Nacional de Mulheres, assim como um texto dentre os vários que constituem a coletânea, intitulado $A$ questão das mulheres no MST, que tem por objetivo “elevar o nível da participação das mulheres na luta pela reforma agrária e na sociedade que queremos construir" (MST, 1998, p. 48).

Para responder qual o papel das mulheres, o texto afirma que

... é o mesmo papel político desempenhado pelos homens, porém do jeito da mulher, ou seja, é o papel de atriz política, com sua característica de gênero feminino e 
de classe trabalhadora e que, por assim ser, é muito mais que estratégia para a resistência nas ações, e muito mais que esposa e mãe somente (MST, 1998, p. 49).

O coletivo afirma que apesar de existirem normas e objetivos específicos para participação das mulheres, até aquele momento essas estavam apenas em papel.

Neste momento, segundo afirmou Stédile em uma entrevista concedida a Fernandes em fevereiro de 1998, ainda não existiam regras para garantir a participação igualitária das mulheres. "A participação das mulheres é definida pelo seu próprio envolvimento com a luta. $\mathrm{Na}$ atual direção nacional, alcançamos a marca de 30\%, mesmo sem ter essa porcentagem estabelecida em normas internas" (Stédile \& Fernandes, 2012, p. 93). Stédile destaca ainda, que desde 1996 o MST começou “... um trabalho específico com mulheres. Há um coletivo nacional que produz material, faz uma reflexão mais teórica sobre a questão de gênero, mas isso não é setor, não significa que todos os Estados tenham coletivos de mulheres" (Stédile \& Fernandes, 2012, p. 95-96).

Com o fito de tirar as normas teóricas do papel e trazer a questão da mulher para a prática, apresentam-se objetivos específicos para a participação das mulheres; metodologias de trabalho; realização de reuniões específicas; e destaque para a participação na formação e na educação.

Esse aprendizado continua quando, em um acampamento, relações de gênero precisam ser radicalmente revistas. Onde os afetos ganham novos significados e novos formatos, nem sempre compatíveis com o código moral de cada família; onde se invertem relações mais usuais, fazendo com que homens também tenham que lavar suas roupas, e mulheres também participem de reuniões e de assembleias, e onde jovens cadastrados passam a ter o mesmo poder de decisão que tem seu pai ou irmão mais velho; onde as crianças passem a ter na comunidade uma referência educadora geralmente mais forte do que sua família, tendo uma existência e uma organização próprias, nem de perto imagináveis em uma comunidade rural típica. (Caldart, 2004, p. 182-183).

No ano de 1999, o Coletivo Nacional de Gênero lançou a cartilha Mulher Sem Terra (1999b), com propostas para oito encontros. As propostas foram fruto “... do MST para fortalecer a participação e organização das mulheres" (MST, 1999b, p. 4). A cartilha traz orientações para a reflexão sobre a realidade e para que as mulheres busquem meios para a construção de uma participação igualitária. Propõe-se um tema a ser discutido em cada encontro, intitulados: as mulheres e a luta de classes; relações de gênero; educar sem discriminar; os valores; cultura e lazer nos assentamentos e acampamentos; mulher e saúde; as mulheres e a construção do 
projeto popular; e as mulheres e a reforma agrária (MST, 1999b, p. 2).

O grande avanço dessa cartilha é a construção do conceito de gênero. $\mathrm{O}$ Movimento aponta a “... importância da mulher no seu desenvolvimento como ser humano, da sua igualdade na diferença com o homem [para construir] ... novas relações de poder ... baseadas em novos valores" (MST, 1999b, p. 11). Para a construção do conceito de gênero foram abordadas as diferenças entre sexo e gênero, sendo o primeiro considerado como biológico e natural, e o segundo uma construção social "... é etiqueta que a sociedade nos impõe do que é ser homem ou ser mulher", a maneira de viver na sociedade como mulheres ou como homem, é apreendida pelos costumes, pela cultura. Conclui que "É cultural. Portanto pode ser mudado!"” (MST, 1999b, p. 12).

Nós mulheres, somos diferentes dos homens, mas não somos inferiores. Politicamente, somos iguais. Existe na sociedade $\mathrm{o}$ masculino $\mathrm{e} o$ feminino, mas está organizada PELO masculino e PARA o masculino, falta a participação do feminino. Queremos é que o ser feminino participe da organização dessa sociedade para que ela seja pensada pelos dois e para os dois. Sendo assim, não dá para continuar falando que existe um papel para a mulher e um papel para os homens. Em nossos Acampamentos e Assentamentos e na nova sociedade, o papel das mulheres é o mesmo papel político desempenhado pelos homens, porém do jeito da mulher. Não queremos ser vistas apenas como mães e esposas, ou simplesmente estar presentes nas ações. Queremos sim, ocupar os espaços de decisões em todos os níveis na nossa organização e na sociedade que almejamos construir.

A cada mulher maltratada pelo machismo, pela violência que o sistema nos impôs há mulheres e homens que lutam e são felizes. Lhe ofertando flores de novas relações de libertação. Quando alguém lhe perguntar: Quem é esse novo homem, essa nova mulher? Onde eles estão? Grita: Eles estão dentro de cada uma e cada um de nós (MST, 1999b, p. 14).

Para ir além das normas, planos e estratégias traçados pelo Coletivo Nacional de Mulheres e ampliar a luta, verificamos que aos poucos vão sendo deixadas para trás as chamadas questões das mulheres e são introduzidas as questões de gênero, como uma categoria mais abrangente, mas não para substituir a categoria mulher. Para fortalecer e envolver todos no debate sobre a questão de gênero, segundo Kelli Mafort (MST, 2014-), membro da coordenação nacional e do setor de gênero do MST, foi criado o setor de gênero em um Encontro Nacional do MST, em 2000, com a tarefa de estimular o debate sobre gênero nas instâncias e espaços de formação, produzir materiais, propor atividades, ações e lutas que contribuíssem para a construção de condições objetivas de participação igualitária aos homens e 
mulheres, fortalecendo o próprio Movimento (MST, 2014-).

O Setor de Gênero tem como principal objetivo levar a discussão para o conjunto do MST, por meio de estudos e reflexões e divulgar cartilhas cujo conteúdo explore a importância de se estabelecer novas relações para se avançar na luta de classes. A criação do Setor de Gênero demonstra, principalmente, a intenção do Movimento em colocar em prática propostas para garantir a igualdade e, também, abrir espaços para que as mulheres possam efetivamente ter voz e poder de decisão. O Setor de Gênero não pretende que o Movimento priorize a luta pela igualdade de gênero em detrimento da luta de classes. Ao contrário, busca-se fortalecer a luta de classes, mas dando oportunidades de participação iguais para todos/as militantes do MST.

O setor de Gênero do MST compreende que discutir e buscar construir novas relações de gênero não está descolado da luta de classes. Ao contrário, entende que essas lutas não podem acontecer separadamente. $\mathrm{O}$ setor luta exatamente para garantir que as mulheres participem do processo de luta pela transformação social como sujeitas da história. Por isso procura garantir que elas tenham iguais oportunidades de militar e dirigir $o$ movimento. Afinal aprendemos na experiência destes 20 anos do MST que é participando que se eleva o nível de consciência. É no processo de formação permanente, com teoria e prática, que vamos deixando de ser objeto para nos transformarmos em sujeitos (as) sociais (MST, 2003, p. 22).

Com a criação do Setor, foram desenvolvidas diretrizes para a política de gênero, como, por exemplo: participação de $50 \%$ de mulheres em todos os espaços do Movimento; nas instâncias de deliberação; nos processos produtivos; de formação e educação e nas mobilizações; debate sobre a ciranda infantil (educação infantil); debate sobre a inclusão do nome da mulher nos documentos de concessão de posse e uso da terra.

A participação de mulheres em todas as ações do MST no estado de Mato Grosso do Sul é expressiva e qualitativa. Muitas estão na 'linha de frente' em mobilizações e em todas as formas de atuação, desde os acampamentos até os assentamentos, e também nos setores influenciando as decisões, criando campos de resistência (Farias, 2011, p. 6).

Em 2001, foi publicado um livro intitulado Construindo o caminho, ou seja, com o mesmo título do livro publicado em 1986. Apesar de possuírem o mesmo título, as obras não apresentam o mesmo conteúdo. O livro publicado em 2001 apresenta a sistematização das experiências do MST até aquele momento em diferentes temas. Neste material temos pela primeira vez a organização das mulheres por meio do Setor de Gênero. 
Conforme a apresentação da publicação, não se trata de um livro, mas de "... uma resenha das reflexões que foram construídas de maneira coletiva" (MST, 2001b, p. 5). Os eixos temáticos pautados nesta publicação são: o modelo econômico e a agricultura; a luta pela reforma agrária e o MST; linhas políticas dos setores do MST; os valores, a disciplina e a mística.

A discussão sobre a mulher encontrase no eixo temático Linhas políticas dos setores do MST, no item Setor de Gênero, sendo o primeiro material que indica a transformação do Coletivo de Mulheres em Setor de Gênero (MST, 2001b, p. 145).

Em 2003, foi elaborada uma nova cartilha pelo Setor Nacional de Gênero, sob o título de Construindo novas relações de gênero: desafiando relações de poder. Esta cartilha adquire um caráter mais teórico e o material serve de orientação para o estudo de homens e mulheres sobre a pauta de gênero. Os seus textos são divididos em oito artigos de diferentes autores/as e têm por títulos: as relações de gênero e o MST; compreendendo o que é gênero; o feminismo e a luta dos trabalhadores; esse negócio de gênero... sei não!; sociedade patriarcal rural, feminismo e educação no século XIX; 8 de março: dia internacional da mulher; desvendando símbolos e significados; uma revolução dentro da revolução, além das sugestões de leitura e glossário.

Os textos abordam a importância do conceito de gênero, como medida para alterar o padrão reproduzido pela sociedade, e transmite valores diferentes daqueles disseminados pela ideologia burguesa. Mostram, ainda, que as desigualdades de gênero estão inseridas na luta de classes e nas desigualdades sociais, então essa discussão deve estar presente no dia a dia do Movimento, nos cursos de formação e nos setores.

Evidente que sendo uma questão sócio cultural, construída e consolidada ao longo da história, não pode se alterar as relações de gênero de uma hora para outra. É necessário todo um processo de transformação de concepção e de comportamento. Mas se não sairmos do campo do discurso para a prática a mudança nunca vão acontecer. Nesse sentido é preciso criar as condições para ir construindo, de fato, relações de gênero baseadas na solidariedade, no companheirismo, cooperação ... (MST, 2003, p. 23).

O livro traz, ainda, no texto As relações de gênero e o MST, que para a transformação da realidade, o discurso deve ser vivenciado, portanto, considera-se fundamental a implementação das linhas políticas do Setor de Gênero, que foram aprovadas pelo conjunto do MST em 1999.

LINHAS POLÍTICAS DE GÊNERO NO MST 
1. Garantir que o cadastro e o documento de concessão de uso da terra seja em nome do homem e da mulher;

2. Assegurar que os recursos e projetos da organização sejam discutidos por toda a família (homem, mulher e filhos que trabalham), e que os documentos sejam assinados e a execução e controle também sejam realizados pelo conjunto da família;

3. Incentivar a efetiva participação das mulheres no planejamento das linhas de produção, na execução do trabalho produtivo, na administração das atividades e controle dos resultados;

4. Em todas as atividades de formação e capacitação, de todos os setores do MST, assegurar que haja $50 \%$ de participação de homens e $50 \%$ de mulheres;

5. Garantir que em todos os núcleos de acampamentos $\mathrm{e}$ assentamentos tenha um coordenador e uma coordenadora que, de fato, coordene as discussões, estudos e encaminhamentos do núcleo, e que participe de todas as atividades como representante da instância;

6. Garantir que em todas as atividades do MST, de todos os setores e instâncias, tenha ciranda infantil para possibilitar a efetiva participação da família (homem e mulher);

7. Assegurar a realização de atividades de formação sobre o tema gênero e classe em todos os setores e instâncias do MST, desde o núcleo de base até a direção nacional;

8. Garantir a participação das mulheres na Frente de Massa e SCA para incentivar as mulheres a ir para o acampamento, participar das atividades no processo de luta, e ser ativa nos assentamentos;

9. Realizar a discussão de cooperação de forma ampla, procurando estimular mecanismos que liberam a família de penosos trabalhos domésticos cotidianos, como refeitórios, lavanderias, etc., comunitários;

10. Garantir que as mulheres sejam sócias de cooperativas e associações com igualdade na remuneração das horas trabalhadas, na administração, planejamento e na discussão política e econômica;

11. Combater todas as formas de violência, particularmente contra as mulheres e crianças que são as maiores vítimas de violência no capitalismo (MST, 2003, p. 25).

Posteriormente, a cartilha Mulheres

Sem Terra: lutando e semeando novas relações de gênero, de 2004 cita avanços como o $1^{\circ}$ Encontro Nacional de Mulheres promovido pelo MST em 1995, e o início da elaboração do conceito de gênero, em 1997, durante o $2^{\circ}$ Encontro Nacional de Mulheres.

Para divulgar a diretriz do combate à violência e à desigualdade, o setor de gênero discute e aprova ações nos congressos, como, por exemplo, para marcar o dia internacional de luta pelo fim da violência contra a mulher, o MST realizou uma Semana de Debates sobre o tema.

Segundo a coordenadora do setor de gênero do MST, Atiliana Bruneto, a 
partir de 2012, o setor iniciou um trabalho de debate e organização de grupos produtivos de mulheres, aliado as outras discussões sobre a questão da participação, violência, problema econômico e da inserção política da mulher na sociedade. Com o objetivo de conscientizar a mulher em relação ao seu processo de vivência, a necessidade de organização e luta por seus direitos (MST, 2016b, p. 1).

Desse modo, a educação do MST vem contribuindo para a formação dos novos valores nas relações de gêneros, que é ao mesmo tempo um processo de luta e de conhecimento.

Um aprendizado correlato a esse foi, e é sempre, o de diálogo entre culturas e histórias diferentes, não apenas na perspectiva do chamado respeito às diferenças, mas muito mais no sentido da construção de novas sínteses históricas e culturais, que superam as tradições comprometidas com projetos sociais excludentes ou discriminatórios. (Caldart, 2004, p. 127-128, grifo no original).

$\mathrm{Se}$ os valores disseminados e impostos são culturais, esses podem e devem ser mudados. Contudo, homens, mulheres e crianças não adquirem, espontaneamente, a consciência da mudança de valores. Por isso, o Movimento busca nas suas práticas educativas e escolares a realização de trabalhos no sentido de avançar na construção de uma consciência de gênero voltada para a igualdade.
Durante todo o período de existência do MST, em 32 anos, consideramos fundamental a participação das mulheres em todos os espaços do movimento. Partindo daí, temos buscado condições de estudar, se informar, dar opiniões, para garantir a nossa participação efetiva. A partir de 2012, o setor de gênero iniciou a construção de grupos de mulheres produtivos. Pois, percebemos que as mulheres somente participam de algumas atividades, quando isso dá uma resposta pra família (MST, 2016b, p. 2).

O documento mais recente produzido pelo Setor de Gênero do MST foi o folheto Mulheres conscientes na luta permanente (MST, 2015). O texto busca esclarecer “... as mulheres sobre o tema da violência em suas diversas expressões. A pobreza, a fome, os conflitos de terra e a publicidade são elementos pontuados como produtores de violência contra as mulheres (Santo, 2016, p. 49).

... esclarecimento sobre o que é a violência doméstica e quais são as dificuldades encontradas por muitas mulheres ao tentarem sair de um quadro de violência: medo de denunciar, não ter para onde ir, dependência financeira, etc. Mas o Setor pontua quatro caminhos coletivos para o enfrentamento deste problema: 1) trazer essa questão para o regimento interno de cada acampamento e assentamento; 2) criar formas para inibir as agressões (apitaço, por exemplo) e levar a pauta para as assembleias; 3) discutir o tema nas escolas com as crianças e adolescentes; 4) acionar a polícia e registrar boletim de ocorrência 
(MST, 2015, apud Santo, 2016, p. 49-50).

Caldart (2004, p. 183) aponta que “essa experiência de inversão de relações tradicionais pode ser tão forte que se torne intolerável para pessoas com condutas já cristalizadas". Temos que considerar que essa inversão tem implicações não só no âmbito do Movimento, mas também no âmbito familiar e na sociedade como um todo, onde ainda impera a lógica machista e patriarcal.

\section{Considerações finais}

Ao longo de sua história, o MST foi construindo um projeto direcionado para igualdade entre homens em mulheres no Movimento. As reflexões e experiências práticas do Movimento proporcionam, de maneira contínua, a elaboração e publicação de documentos que trazem contribuições teóricas e empíricas para a atualidade.

Nos primeiros documentos (MST, 1988) o Movimento já apresentava as dificuldades a serem ultrapassadas para a conquista da igualdade de gênero. Aos poucos foi definindo sua política de gênero, de forma teórico-prática, e incorporando os novos valores aos seus cursos de educação formal e de formação política. As diretrizes políticas para a questão de gênero, definidas pelo
Movimento, estão em acordo com a sua pedagogia, pautada na formação do ser humano por meio de práticas e vivências. Ao mesmo tempo, as mulheres Sem Terra foram se organizando interna e externamente para a luta contra o machismo e a violência, e pela ampliação e garantia de direitos.

Nos documentos analisados dos diferentes setores do MST, Caderno de Formação (1986a, 1986b, 1987, 1988), Caderno de Estudo (1998, 2001b, 2003, 2004a, 2015), Cartilhas (1996a, 1996b, 1998, 1999b) observamos várias orientações no sentido da inclusão das mulheres na produção, nas instâncias decisórias, coordenações políticas, com destaque na importância da participação da mulher.

A criação do Setor de Gênero foi uma das decisões mais importantes tomadas pelo Movimento no sentido de fortalecer a luta por esse tipo de igualdade. O trabalho realizado pelo Setor ampliou a discussão sobre gênero no interior do MST, elaborou vários textos para publicação e desencadeou ações para impulsionar a participação das mulheres e a luta contra a violência.

Podemos afirmar que o MST está construindo uma formação educacional que auxilia na mudança de valores, forjando uma nova sociabilidade. Para essa 
construção é necessário, primeiro, romper com os valores dominantes na sociedade capitalista e, segundo, cultivar de imediato os novos valores denominados de humanistas e socialistas. Dentre esses valores citamos especialmente "... a busca da igualdade combinada com o respeito às diferenças culturais, de raça, de gênero e de estilos pessoais" (MST, 1996a, p. 09).

De acordo com os documentos analisados, o desejo e o trabalho para mudar os valores hegemônicos vêm sendo compartilhados pelos integrantes do MST, em todos os setores, incluindo a formação educacional das crianças e jovens.

É preciso sim, que se mude o que pode ser mudado. Nós devemos educar nossas filhas mulheres para que sejam doces, educadas, carinhosas, sim, mas sem que necessariamente sejam submissas. E devemos educar nossos filhos homens para que sejam doces, carinhosos, e educados, sim, sem que percam a sua masculinidade (MST, 1999b, p. 17-18).

As relações de gênero entre os militantes são, para o Setor de Gênero do Movimento, um dos principais assuntos a ser estudado. A indicação é que homens e mulheres construam a igualdade, oportunidades e para que suas ações pautem-se nos princípios pedagógicos e filosóficos, que devem ser implantados em todos os acampamentos, assentamentos, espaços de lutas e, principalmente, nas escolas e na formação política dos militantes.

Todos os textos aqui apresentados e que foram produzidos pelos coletivos de mulheres e/ou setor de gênero trazem propostas estratégicas para promover a igualdade de gênero, com o fito de garantir uma participação igualitária de todos/as integrantes do Movimento. Portanto, a discussão do tema, realização de seminários e uma nova formação educacional vêm contribuindo para a construção de novos valores.

Segundo Melo (2007, p. 138), tem sido possível observar mudanças concretas significativas, tais como a inclusão de pelo menos um dia de discussão específica sobre o tema das desigualdades nas relações sociais de gênero nos encontros nacionais e estaduais, e a organização de oficinas e cursos de formação massivos voltados para a discussão do tema. Acrescentamos, ainda, que todos os coletivos do MST têm um coordenador e uma coordenadora, que ocupam a função por tempo determinado para todos os homens e mulheres possam obter a experiência de direção.

\section{Referências}

Araujo, D. M. O. (2014). Movimentos sociais: questões de gênero e educação na Experiência do MST. Salvador. Recuperado de 
http://www.reformaagrariaemdados.org.br/ biblioteca/artigos?field_bib_ano_value $\% 5$ Bvalue\%5D\%5Byear\%5D=\&title=Movim entos+Sociais\%3A+quest\%C3\%B5es+de+ g\%C3\%AAnero+e+educa\%C3\%A7\%C3\% A3o+na+Experi\%C3\%AAncia+do+MST\& name $=$

Bauer, C. (2009). Educação, terra e liberdade: princípios educacionais do MST em perspectiva histórica. São Paulo, SP: Edições Pulsar.

Caldart, R. S. (2004). Pedagogia do Movimento Sem Terra. São Paulo, SP: Expressão Popular.

Farias, M. F. L. (2011). Mulheres no Movimento dos Trabalhadores Rurais Sem Terra (MST). In Anais do XXVI Simpósio Nacional de História - ANPUH. São Paulo.

Gonçalves, R. (2010). De companheira "acompanhante" à companheira de luta: as mulheres na luta pela terra do MST. In Fazendo gênero: diásporas, diversidades, deslocamentos. Florianópolis, SC: UFSC.

Jornal Sem Terra (JST). (nov., 1995). Sem a luta das mulheres, as conquistas ficam pela metade. São Paulo.

Jornal Sem Terra (JST). (mar., 1996) $O$ MST deve lutar também contra o machismo. São Paulo.

Melo, D. M. (2007). Subjetividade e gênero no MST: observações sobre documentos publicados entre 1979 e 2000 In Gohn, M. G. (Org.). Movimentos sociais no início do século XXI (pp. 113-143). Petrópolis, RJ: Vozes.

Movimento dos Trabalhadores Rurais Sem Terra (MST). (1986a). Organização do Movimento. Quem é quem na luta pela terra. Caderno de Formação. MST, s.1, (1).
Movimento dos Trabalhadores Rurais Sem Terra (MST). (1986b). A luta continua: como se organizam os assentados. Caderno de Formação, (10). São Paulo.

Movimento dos Trabalhadores Rurais Sem Terra (MST). (1987). $\quad 3^{\circ}$ Encontro Nacional: nossas prioridades. Caderno de Formação, (12). São Paulo.

Movimento dos Trabalhadores Rurais Sem Terra (MST). (1988). A mulher nas diferentes sociedades. Caderno de Formação, (15). São Paulo, SP: Secretaria Nacional do MST.

Movimento dos Trabalhadores Rurais Sem Terra (MST). (1989). Normas gerais do MST. São Paulo, SP: MST.

Movimento dos Trabalhadores Rurais Sem Terra (MST). (1992a). Como deve ser a escola de assentamento. Ocupar, resistir e produzir também na educação. Boletim da Educação, (01), Setor de Educação, Porto Alegre.

Movimento dos Trabalhadores Rurais Sem Terra (MST). (1992b). Como fazer a escola que queremos. Caderno de Educação, (01), São Paulo.

Movimento dos Trabalhadores Rurais Sem Terra (MST). (1994). Alfabetização de jovens e adultos - educação matemática. Caderno da Educação, (5). São Paulo.

Movimento dos Trabalhadores Rurais Sem Terra (MST). (1996a). Princípios da educação no MST. Caderno da Educação, (8). Porto Alegre.

Movimento dos Trabalhadores Rurais Sem Terra (MST). (1996b). A Questão da Mulher no MST. São Paulo, SP: Coletivo Nacional de Mulheres do MST. 
Movimento dos Trabalhadores Rurais Sem Terra (MST). (1998). Compreender $e$ construir novas relações de gênero. São Paulo, SP: Coletivo Nacional de Gênero. Peres.

Movimento dos Trabalhadores Rurais Sem Terra (MST). (1999a). Como fazemos a escola de educação fundamental. Caderno de Educação, (9). Rio Grande do Sul.

Movimento dos Trabalhadores Rurais Sem Terra (MST). (1999b). Mulher Sem Terra. Caderno de Formação, (2). São Paulo.

Movimento dos Trabalhadores Rurais Sem Terra (MST). (2001b). Construindo o caminho. São Paulo, SP: MST.

Movimento dos Trabalhadores Rurais Sem Terra (MST). (2003). Construindo novas relações de gênero: desafiando relações de poder. As relações de gênero e o MST. In Campos, C. (Org.). Setor Nacional de gênero. MST. São Paulo, SP: ANCA.

Movimento dos Trabalhadores Rurais Sem Terra (MST). (2004). Mulheres Sem Terra lutando e semeando novas relações de gênero: 8 de março dia Internacional da Mulher Trabalhadora. São Paulo, SP: Peres.

Movimento dos Trabalhadores Rurais Sem Terra (MST). (2005). Dossiê MST Escola Documentos e Estudos 1990 - 2000. Caderno de Educação n 13. Agosto de 2005, Veranópolis, RS: Iterra.

Movimento dos Trabalhadores Rurais Sem Terra (MST). (2014). Mulheres do MST criam novas relações de gênero dentro $e$ fora do movimento. Recuperado de http://antigo.mst.org.br/node/15654.

Movimento dos Trabalhadores Rurais Sem Terra (MST). (2015). Mulheres conscientes na luta permanente. São Paulo.
Movimento dos Trabalhadores Rurais Sem Terra (MST). (2016a). Apresenta informações sobre o MST. Recuperado de http://www.mst.org.br/nossa-historia/84$\underline{86}$.

Movimento dos Trabalhadores Rurais Sem Terra (MST). (2016b). Procuramos construir novas relações de gênero, em que todas e todos sejamos respeitosos um com o outro. Recuperado de http://www.mst.org.br/2015/11/25/procura mos-construir-novas-relacoes-de-generoem-que-todas-e-todos-sejamos-respeitososum-com-o-outro-afirma-dirigente.html.

Santo, T. M. (2016). As publicações do setor de gênero do MST e as vivências de mulheres Sem Terra: reflexões sobre desrespeito, reconhecimento e autonomia (Dissertação de Mestrado). Pontifícia Universidade Católica do Rio Grande do Sul, Porto Alegre.

Stédile, J. P., \& Fernandes, B. M. (2012). Brava Gente: a trajetória do MST e a luta pela terra no Brasil. São Paulo, SP: Expressão Popular.

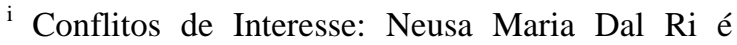
membro do Conselho Editorial Nacional da Revista Brasileira de Educação do Campo e não participou do processo de avaliação do artigo. ii Para ampliar a luta pela igualdade, o MST deixou
para trás as chamadas questões das mulheres e
introduziu as questões de gênero, por considerar
uma categoria mais abrangente. Todavia, a
documentação do MST não traz discussões ou
orientações sobre temas ligados ao movimento dos
LGBTT.
}

Recebido em: 30/07/2017

Aprovado em: 14/08/2017

Publicado em: 11/09/2017 
Como citar este artigo / How to cite this article / Como citar este artículo:

APA:

Pessôa, J. R., \& Dal Ri, N. M. (2017). Movimento dos Trabalhadores Rurais Sem Terra e a formação para a igualdade de gênero. Rev. Bras. Educ. Camp., 2(2), 581-606. DOI: http://dx.doi.org/10.20873/uft.2525$\underline{4863.2017 v 2 n 2 p 581}$

\section{ABNT:}

PESSÔA, J. R.,; DAL RI, N. M. Movimento dos Trabalhadores Rurais Sem Terra e a formação para a igualdade de gênero. Rev. Bras. Educ. Camp., Tocantinópolis, v. 2, n. 2, p. 581-606, 2017. DOI: http://dx.doi.org/10.20873/uft.2525-

4863.2017v2n2p581

\section{ORCID}

Jeniffer Ribeiro Pessôa

iD http://orcid.org/0000-0003-3126-2559

Neusa Maria Dal Ri

iD http://orcid.org/0000-0002-3000-2280 